Corrigendum

\title{
Corrigendum to "Parents' and early adolescents' self-efficacy about anger regulation and early adolescents' internalizing and externalizing problems: A longitudinal study in three countries" [Journal of Adolescence 64 (2018) 124-135]
}

\author{
${ }^{a}$ Psychology Department, Sapienza University of Rome, Italy \\ b Psychology Department, University of North Carolina, Wilmington, USA \\ ${ }^{\mathrm{c}}$ Center for Child and Family Policy, Duke University, USA \\ d Psychology Department, Arizona State University, USA \\ e Psychology Department, Second University of Naples, Italy \\ ${ }^{\mathrm{f}}$ Psychology Department, Universidad San Buenaventura, Colombia
}

Laura Di Giunta ${ }^{\mathrm{a}, *}$, Anne-Marie R. Iselin ${ }^{\mathrm{b}}$, Jennifer E. Lansford ${ }^{\mathrm{c}}$, Nancy Eisenberg ${ }^{\mathrm{d}}$, Carolina Lunetti $^{\mathrm{a}}$, Eriona Thartori ${ }^{\mathrm{a}}$, Emanuele Basili ${ }^{\mathrm{a}}$, Concetta Pastorelli ${ }^{\mathrm{a}}$, Dario Bacchini ${ }^{\mathrm{e}}$, Liliana Maria Uribe Tirado ${ }^{\mathrm{f}}$, Maria Gerbino ${ }^{\mathrm{a}}$

The authors regret that the following errors were present in the above-mentioned article.

Page 126

2.1. Sample

1st line

"Participants were recruited from the longitudinal blinded for review Study (e.g., blinded for review)."

Should read:

"Participants were recruited from the longitudinal Study entitled Parenting Across Cultures (e.g., Lansford et al., 2014)."

Page 127

2.1. Sample

8th line

"Over $81 \%$ of mothers, $77 \%$ of fathers, and $81 \%$ of children from the initial sample (see Blinded) . Study provided data at T1." Should read:

"Over $81 \%$ of mothers, $77 \%$ of fathers, and $81 \%$ of children from the initial sample of Parenting across Cultures Study provided data at T1."

Page 129

2.3.2. Early adolescents' self-efficacy beliefs about anger regulation (T2)

7th line

"We examined youths' answers about how well they could deal with their anger in the three out of six vignettes ( $1=$ not at all well $5=$ very well) that had the highest factor loadings in a confirmatory factor analysis conducted with this same sample (Blinded for review)."

Should read:

"We examined youths' answers about how well they could deal with their anger in the three out of six vignettes $(1=$ not at all well -

\footnotetext{
DOI of original article: http://dx.doi.org/10.1016/j.adolescence.2018.01.009

* Corresponding author.

E-mail address: laura.digiunta@uniroma1.it (L. Di Giunta).
} 
$5=$ very well) that had the highest factor loadings in a confirmatory factor analysis conducted with this same sample (Di Giunta et al., 2017)."

Page 135

References

41st line

The following reference is missing from the reference section:

Lansford, J. E., Sharma, C., Malone, P. S., Woodlief, D., Dodge, K. A., Oburu, P., ... \& Tirado, L. M. U. (2014). Corporal punishment, maternal warmth, and child adjustment: A longitudinal study in eight countries. Journal of Clinical Child \& Adolescent Psychology, 43(4), 670-685.

The authors would like to apologise for any inconvenience caused. 